\title{
A Study on the Healing Rest Space in Pediatric Ward
}

\author{
소아병동의 치유적 휴게공간에 관한 연구
}

Jung, So Young * 정소영 | Kim, Ye-Seul** 김예슬 | Choi, Kwangseok*** 최광석

\begin{abstract}
Purpose: Many researches have clearly begun to address the relationship between people and their physical environments. These represent that children experience traditional hospital environments as unpleasant and scary. More specifically, children in hospitals face many psychological and emotional challenges: isolation, painful procedures, separation from family members, all in unfamiliar settings. For this reason, some have argued that the children's experiences within hospital environments can lead to poorer health outcomes. This study has been started in order to provide basic informations for the planning of Healing rest space in pediatric ward. Methods: Literature reviewes and field surveys to rest space at pediatric ward in Korea and foreign country have been conducted for the data collection. Results: The result of this study can be summarized into eight environment factor for healing rest space in pediatric ward: family, noise, safe, choice opportunity, light, privacy, social support and distract from disease or death. Implications: In the rest space in pediatric ward, it is necessary to consider healing rest space for promoting healing from disease and normal developing of children.
\end{abstract}

Keywords Children's Hospital, Healing Environments, Rest Space, Evidence-Based Design

주 제 어 소아병동, 치유환경, 휴게 공간, 근거기반 디자인

\section{Introduction}

\subsection{Background and Objective}

최근의 의료시장은 양적 성장시대가 지나고, 의료시설 간 환경적 경쟁이 진행되어 왔다. 그 결과, 보다 나은 의료 서비스의 제공과 더불어 진료중심의 의료체계가 이용자 중 심의 의료체계로 전환되고 있다(박진규, 2011). 이것은 기 존의 진료중심 환경에서 시설을 이용하는 모든 사람의 스 트레스를 줄여주고, 환자의 치유활동을 활성화시키는 환경 으로의 변화를 의미한다. 따라서 최근의 의료시설은 기능이 충실한 건축을 지향하는 동시에 이용자의 요구에 맞는 특 성화, 전문화되는 경향을 가지게 되었는데, 이러한 경향의 일환으로 어린이를 위한 병원과 병동이 생기게 되었다.

어린이 환자는 성인과는 다르게 질병의 치유뿐만 아니라 정상적인 성장발달을 위한 환경적 자극이 필요한 대상이다.

\footnotetext{
* Member, A candidate for the Ph.D., PNP, Department of Nursing, Hanyang University, Seoul, Korea (Primary \& Corresponding author: smilejsy1@hanyang.ac.kr)

** Masters student, Department of Architecture, Hanyang University, Seoul, Korea (yeseulkim3@hanyang.ac.kr)

*** Editor, Ph.D., Korea Institute of Hospital Architecture (daumchois@hanmail.net)
}

어린이는 발달과정상 주위 환경변화에 매우 민감하여 질병 자체로 인한 고통 외에도, 진단 치료과정과 입원생활 환경 으로부터 쉽게 스트레스를 받으며, 이것은 질병의 치유과정 에 큰 영향을 미칠 수 있다. 또한 어린이를 위한 입원환경에 는 가족에 대한 배려가 매우 중요한데, 가족은 어린이에게 건강의 회복뿐만 아니라 성장 발달 전반에 영향을 미치는 중요한 존재이기 때문이다. 즉, 어린이를 위한 의료시설, 특 히 입원시설은 환경에 대한 고려가 매우 중요하다.

현재, 국내의 병원급 이상의 의료기관 중 어린이 전문병 원은 13 개소로 제 외국과 비교할 때(미국 약 230 곳, 일본 28곳), 양적으로 매우 적은 상황이지만(최지은 \& 박수빈, 2011), 종합 병원에는 어린이를 위한 소아과 병동이 거의 (96.5\% 이상) 설치되어 있다(이신호 et el., 2006). 또한 소 아과 병동에는 일반 성인병동과는 다르게 소아를 위한 휴 게실, 혹은 놀이방이 대부분 설치되어 있는데, 소아과 외 래 대기실의 형태와 비교했을 때, 아직 열악한 경우가 많다. 즉, 외래 대기공간은 어린이 놀이시설뿐만 아니라 수유 공 간 등 이용자의 편의에 맞추어진 환경을 구축해 놓는 경우 가 많지만, 입원하여 외부 놀이시설을 이용하지 못하는 어 린이들이 실제로 이용하는 병동 내 휴게공간은 그렇지 못 한 것이 현실이다. 따라서 어린이 전문병원의 증축 및 개축 
과 같은 양적 성장도 필요하지만, 기존 소아과 병동의 휴게 실 및 놀이방의 환경 개선이 어린이에게 치유적인 환경을 조성하는 일로서 보다 우선시 되어야 할 것이다.

본 연구는 이러한 배경 하에서, 기존 어린이 병동의 휴게 실 또는 놀이방을 아동 및 가족을 위한 치유공간으로 계획 하고자 하였다.

\subsection{Methods of Research}

본 연구는 어린이 병동의 치유적인 휴게 공간 계획을 위 하여 어린이의 특성과 어린이병동 휴게공간에 관한 문헌고 찰을 통해 환경요소를 추출하고 이에 대한 현장 및 설문조 사를 하였다.

첫째 어린이의 특성과 어린이 병동의 휴게 공간에 관한 문헌분석을 통해, 어린이의 신체적, 인지적, 사회정신적인 특성과 입원으로 인한 특성 등을 확인하고, 근거기반의 치 유적 환경 요소를 추출하였다.

둘째 추출한 분석 틀을 통해 국내와 해외 어린이 병동 휴 게 공간의 현황 및 설문조사를 실시하였다.

셋째 문헌고찰 및 수집된 자료의 분석을 통해 치유적 휴 게 공간에 대한 계획적 개선방안을 제시하였다.

\section{Theoretical Consideration}

\subsection{Children's Characteristics}

국내 85개 수련병원의 자료를 분석한 연구 보고서(이종 국, 2007)에 따르면, 소아과 병동에 입원하는 환자의 연령 은 1 5세까지의 유아 및 학령전기 아동이 $34.4 \%$ 로 가장 많았고, 5 10세 19.1\%, 10 18세까지의 청소년기 환자가 $17.2 \%, 1$ 개월 1 세까지의 영아가 $15.8 \%$ 순이었다. 즉, 어 린이 병동에는 다양한 연령대의 아동이 입원을 하게 되는 데, 각 단계에 따라 독특한 성장 발달 특성을 갖고 있다.

아동의 성장과 발달은 신체적인 면뿐만 아니라, 인지적 발달, 사회 심리적 발달로 나누어 생각할 수 있다. 이러한 아 동의 종합적인 연령별 발달특성을 [Table 1]에 정리하였다.

영아기는 신체성장이나 발달이 급속도로 이루어지는 시 기이다. 생후 1 년까지 몸무게가 출생 당시에 비해 3 배까 지 증가하고, 신장 역시 $50 \%$ 이상 증가된다. 또한 원시반

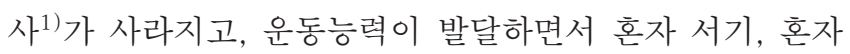
걷기가 가능해진다. 이 시기의 아기들은 자극에 대한 반응 을 보이고, 여러 단어의 의미를 인식할 수 있게 된다. 또한 까꿍 놀이와 같이 물체의 변화나 사람의 행동 변화에 대하 여 반응하게 된다.

유아기 아동은 신체발달의 속도가 영아기 때보다는 늦어 지고, 체중보다는 신장의 증가율이 높아진다. 이 시기의 아 동은 근골격계와 신경이 발달하면서 수많은 시도와 반복을 통해 여러 가지 복잡한 동작이나 기술을 습득하게 된다. 즉,
혼자 옷을 입거나, 점프가 가능해진다. 어떤 사건의 원인과 결과를 인식하기 시작하지만, 또래 간의 관계 형성보다는 병행놀이 (parallel play) ${ }^{2)}$ 를 주로 하게 된다.

학력전기 아동은 신체조절능력이 확립됨에 따라 옷 입 기, 배설하기, 음식물 섭취 등을 스스로 조절하지만, 자아 중심적 사고가 여전히 존재한다. 어떤 것을 나타내는 상징 물에 대해 인식할 수 있게 되고, 부모와의 이별을 좀 더 긴 시간 동안 견딜 수 있게 된다. 그리고 이 시기부터 또래와의 협력적 활동이 가능해져서 함께 노는 것을 좋아하게 된다.

학령기 아동은 신체발달이 비교적 완만하게 진행되면서 전체적인 신체 체계가 안정된다. 그 결과, 운동기술은 더욱 정교화 되어 기본적인 뛰기, 균형 잡기, 스포츠 활동 등을 잘 할 수 있게 된다. 인지기능이 발달하면서 문제 해결력이 증가하고, 새로운 지식을 얻는데 적극적이다. 이 시기에는 많은 시간을 학교에서 친구들과 함께 스포츠나 다른 활동 을 하면서 보내는 것을 좋아하게 된다.

청소년기가 되면서 성적 성숙 및 신체적 변화가 급속히 진행된다. 2 차 성장이 나타나고, 추상적 사고가 가능해지 며, 독립성이 발달하게 된다. 이 시기에는 특히, 또래 관계 를 중요하게 생각하여 친구와 보내는 시간을 소중히 여기 게 된다.

이상과 같이, 아동은 연령에 따라 다양한 성장 발달 특성 을 가지게 되는데, 이에 따라 입원에 대한 아동의 정서 또한 다르게 나타나게 된다.

\subsection{Stressors of Hospitalized Children}

일반적으로 입원환경이 어린이 환자들에게 즐겁지 않고, 두려운 경험을 가지게 한다는 것은 이미 널리 알려져 있는 사실이다(Blumberg, 2006). 특히, 병원에 입원한 아동은 여러 가지 정 서적, 정신적인 도전(고립감, 고통을 주는 처 치, 가족구성원들과의 격리, 친숙하지 않은 환경 등)에 직 면하게 된다(Eisen et al., 2008: 175). 이러한 이유로, 여러 학자들은 병원에서 아동의 경험이 건강에 좋지 않은 결과 를 가져 올 수 있다고 주장하고 있다(Koller and mclaren, 2012). 입원으로 인한 아동의 연령별 스트레스 및 그에 따 른 반응, 또한 그러한 반응을 줄이기 위해 필요한 치유적 환 경요소를 [Table 2]에 정리하였다.

영아기의 아기는 입원과 관련하여 격리 불안과 낮선 환 경에 대한 불안감을 느끼게 되어 일상적인 생활의 리듬이 깨지게 된다. 이러한 낮선 환경은 영아들에게 과도한 자극 (소음이나, 빛)을 주어 수면 패턴에 변화가 생기게 되고, 정 상적인 수유양상의 변화를 가져온다. 또한, 신체발달이 빠

1) 일반적으로 태어나면서부터 보이는 반사작용으로 빨기반사, 바빈스 키반사, 모로반사 등이 포함된다.

2) 병행놀이는 또래와 협력해서 노는 것이 아니라 동시병행으로 다른 놀이를 하는 것을 말한다. 
르게 진행되는 시기인 영아의 경우, 몸의 움직임 자체가 발 달을 촉진하는 계기가 되는데, 그것이 억제되었을 때, 그 자 체가 스트레스로 작용될 수 있다. 아직 미세근육까지 충분 히 발달하지 못한 점을 고려할 때, 영아들은 안전한 환경에 서 충분한 움직임이 가능한 공간이 필요하다.

유아기 아동은 영아기와 마찬가지로 격리 불안이나 낮선 환경에 대한 불안감을 느끼는 동시에, 어두움에 대한 두려 움을 가지고 있으면서 자신의 몸을 스스로 조절하지 못하 는 상실감을 느낀다. 또한 병원에서의 진단, 치료과정에 대 한 두려움이 특히 커지는 시기이다. 따라서 어둡지 않으면 서 스스로 움직일 수 있는 환경을 유지할 수 있어야 한다.

학령전기 아동은 일반적으로 격리 불안 외에 신체손상이 나 통증에 대한 두려움이 크고, 자기 조절력의 감소에 대한 상실감, 어두움에 대한 공포를 가지게 된다. 따라서 유아기 와 마찬가지로 어둡지 않고 스스로 선택할 수 있는 환경이 필요하다.
학령기 아동은 학령전기와 마찬가지로 자기 조절력의 감 소에 대한 상실감을 느끼지만, 이전과는 다르게 친구들과의 분리에 대한 걱정을 느끼면서 죽음에 대한 두려움을 가지 게 된다. 따라서 스스로 선택할 수 있는 활동이나 공간이 필 요하고, 입원해 있는 다른 또래와의 관계를 지지할 수 있는 공간이 필요하다.

마지막으로 청소년은 친구들과의 분리에 대한 두려움이 많아지면서 신체의 변화에 대해 민감하고, 프라이버시 유지 에 특히 신경을 쓰게 된다(Ball \& Bindler, 2007). 따라서 청소년을 위해서는 또래 관계의 유지 및 개인의 활동을 지 지해 줄 수 있는 환경이 필요하다.

다시 말하면, 입원으로 인한 스트레스에 대한 반응은 연 령에 따라 다양하게 나타나는데, 그러한 반응들은 아동의 정상적 성장 발달 및 질병치유에 부정적인 결과를 가져오 게 된다. 따라서 이러한 스트레스를 줄여주는 환경이 고려 되어야 한다.

[Table 1] Growth and Development of Children

\begin{tabular}{|c|c|c|c|}
\hline & $\begin{array}{c}\text { Physical Growth and } \\
\text { Development }\end{array}$ & Cognitive Development & Psychosocial Development \\
\hline $\begin{array}{l}\text { infant } \\
\text { (birth to } 1 \text { year) }\end{array}$ & $\begin{array}{l}\text { - triples birth weight by } 1 \text { year } \\
\text { - stand alone } \\
\text { - pick up small objects } \\
\text { - plays peek-a-boo }\end{array}$ & $\begin{array}{l}\text { - the infant receives stimulation } \\
\text { through sight, sound, and feeling, } \\
\text { which the maturing brain interprets. } \\
\text { - 1-year-old turns to sound and } \\
\text { recognizes its significance. } \\
\text {-1-year-old says a few words and } \\
\text { understands many more. } \\
\text {-1-year-old reaches for toys and } \\
\text { self-feeds. }\end{array}$ & $\begin{array}{l}\text { - enjoys large blocks } \\
\text { - laughs at surprise toys like jack-in- } \\
\text { the-box } \\
\text { - plays interactive game like peek-a- } \\
\text { boo } \\
\text { - understands 'no' and other simple } \\
\text { commands } \\
\text { - receptive speech surpasses } \\
\text { expressive speech }\end{array}$ \\
\hline $\begin{array}{c}\text { toddler } \\
\text { (1 to } 3 \text { years) }\end{array}$ & $\begin{array}{l}\text { - draws a circle and other } \\
\text { rudimentary forms } \\
\text { - learning to dress self } \\
\text { - jumps, kick ball, throws ball } \\
\text { overhand }\end{array}$ & $\begin{array}{l}\text { - object permanence is well } \\
\text { developed. } \\
\text { - rudimentary problem solving, } \\
\text { creative thought, and an } \\
\text { understanding of cause-and- } \\
\text { effect realtionships are possible }\end{array}$ & $\begin{array}{l}\text { - parallel play } \\
\text { - push and pull objects; climb in and } \\
\text { out; up and down; run, ride a Big } \\
\text { wheel; turn the pages of books. } \\
\text { - imitate words and speech intonations } \\
\text { as well as the social interactions } \\
\text { they observe. }\end{array}$ \\
\hline $\begin{array}{l}\text { preschool child } \\
\text { (3 to 6years) }\end{array}$ & $\begin{array}{l}\text { - climb well, rides tricycle or } \\
\text { bicycle with training wheels } \\
\text { - learns letters and numbers }\end{array}$ & $\begin{array}{l}\text { symbols or words are used to } \\
\text { represent objects and people, } \\
\text { enabling the young child to think } \\
\text { about them. }\end{array}$ & $\begin{array}{l}\text { - play with other children is a favorite } \\
\text { activity } \\
\text { - associative play is facilitated by } \\
\text { simple games, puzzles, nursery } \\
\text { rhymes, songs }\end{array}$ \\
\hline $\begin{array}{c}\text { school-age } \\
\text { child } \\
\text { (6 to 12years) }\end{array}$ & $\begin{array}{l}\text { - jump rope, can read } \\
\text { - concentrates on activities for } \\
\text { longer periods }\end{array}$ & $\begin{array}{l}\text { - can consider alternative solutions } \\
\text { and solve problems } \\
\text { - learns the concept of conservation }\end{array}$ & $\begin{array}{l}\text { - cognitive growth is facilitated by } \\
\text { reading, crafts, word puzzles, school } \\
\text { work. } \\
\text { - mature use of language } \\
\text { - spends many hours at school } \\
\text { and with friends in sports or other } \\
\text { activities }\end{array}$ \\
\hline $\begin{array}{c}\text { adolescent } \\
\text { (12 to } 18 \text { years) }\end{array}$ & $\begin{array}{l}\text { - growth spurt } \\
\text { secondary sexual } \\
\text { characteristics begin to } \\
\text { develop }\end{array}$ & $\begin{array}{l}\text { - develops the ability to reason } \\
\text { abstractly. } \\
\text { - the ability to think and act } \\
\text { independently leads many } \\
\text { adolescents to rebel against } \\
\text { parental authority. }\end{array}$ & $\begin{array}{l}\text { - sports, school activities, quiet } \\
\text { activities } \\
\text { - increasing communication and time } \\
\text { with peer group } \\
\text { - applying abstract thought and } \\
\text { analysis in conversations at home } \\
\text { and school }\end{array}$ \\
\hline
\end{tabular}


이상과 같은 각 연령에 따른 치유적 환경은 [Table 2]에 제시된 치유환경요소들을 고려해야 한다. 치유환경요소 중 가변 공간(movable space)은 선택권(choice opportunity)의 범주에 포함시켰다. 즉, 어린이 병동의 휴게공간에 서 고려되어야 할 치유적 환경요소는 (1) 가족이 함께 할 수 있는 환경, (2) 소음, (3) 안전, (4) 선택권, (5) 빛, (6) 프라이버 시 지원 환경, (ㄱ) 사회적 지지 (또래 관계를 지지할 수 있는 환경), (8) 기분전환을 위한 환경(distract from disease or death)이다.

\subsection{Healing Rest Space in Pediatric Ward}

앞에 제시한 어린이 병동의 휴게공간에 필요한 치유적 요소는 아동의 성장 발달뿐만 아니라 입원한 아동의 반응 을 고려하여 추출한 요소들이다.

1) Family

어린이 전문병원의 디자인 및 계획에서 중요한 심리적
요소 중 하나는 가족이다(Malkin, 1992). 어린이 환자가 부 모와 함께 있는 것은 어린이와 부모 모두에게 도움이 되는 데, 특히, 어린이 환자에게 부모의 존재는 익숙하지 않은 병 원을 일상적인 환경으로 인식하는데 도움을 준다(최지은, 박수빈, 2011). 스몰(Small, 2002)은 어린이의 나이가 어 릴수록 가족과의 분리로 인한 고통이 더욱 심해져서 입원 으로 인한 부정적 정서가 커진다고 하였다. 또한 어린이를 돌보는 가족 구성원은 아픈 어린이들을 항상 걱정하고 지 켜보려 함으로서. 어린이 환자를 위한 공간에는 가족이 함 께 할 수 있는 공간계획이 필히 포함되어야 한다. 즉, 아동 을 위한 병동에는 가족을 배려할 수 있는 공간이 마련되어 야 한다.

\section{2) Noise}

소음은 불안, 괴로움 등을 초래함으로서, 정신적 신체적 스트레스를 발생시키고, 심박동수의 증가와 혈압 증가와 같 은 신체적 증상이 나타난다(Ulrich, R. S. et al., 2008). 특

[Table 2] Stressors of hospitalization for children at various developmental stages and healing environmental factors

\begin{tabular}{|c|c|c|c|}
\hline & Stresors & Responses & Healing Environmental Factors \\
\hline $\begin{array}{c}\text { infant } \\
\text { (birth to } 1 \text { year) }\end{array}$ & $\begin{array}{l}\text { - separation anxiety } \\
\text { - stranger anxiety } \\
\text { - painful, invasive procedure } \\
\text { - immobilization } \\
\text { - sleep deprivation, sensory } \\
\text { overload }\end{array}$ & $\begin{array}{l}\text { - sleep-awake cycle disrupted } \\
\text { - feeding routines disrupted } \\
\text { - displays exessive irritability }\end{array}$ & $\begin{array}{l}\cdot \text { family } \\
\cdot \text { noise } \\
\cdot \text { - safety } \\
\cdot \text { movable space }\end{array}$ \\
\hline $\begin{array}{c}\text { toddler } \\
\text { (1 to } 3 \text { years) }\end{array}$ & $\begin{array}{l}\text { - separation anxiety } \\
\text { - loss of self-control } \\
\text { - immobilization } \\
\text { - painful, invasive procedure } \\
\text { - bodily injury or mutilation } \\
\text { - fear of the dark }\end{array}$ & $\begin{array}{l}\text { - is frightened if forced to lie } \\
\text { supine } \\
\text { - associates pain with punishment } \\
\text { - wonders why parents don't } \\
\text { come to the rescue }\end{array}$ & $\begin{array}{l}\text { - family } \\
\text { - movable space } \\
\text { - choice opportunity } \\
\text { - safety } \\
\text { - light }\end{array}$ \\
\hline $\begin{array}{l}\text { preschool child } \\
\text { (3 to 6years) }\end{array}$ & $\begin{array}{l}\text { - separation anxiety and fear of } \\
\text { abandonment } \\
\text { - loss of self-control } \\
\text { - painful, invasive procedure } \\
\text { - bodily injury or mutilation } \\
\text { - fear of the dark }\end{array}$ & $\begin{array}{l}\text { - displays difficulty separating } \\
\text { reality from fantasy. } \\
\text { - fears ghosts and monsters } \\
\text { - fears body parts will leak out } \\
\text { - demonstrates withdrawal, } \\
\text { projection, aggression, } \\
\text { regression }\end{array}$ & $\begin{array}{l}\text { - family } \\
\text { - choice opportunity } \\
\text { - safety } \\
\text { - light }\end{array}$ \\
\hline $\begin{array}{l}\text { school-age child } \\
\text { ( } 6 \text { to 12years) }\end{array}$ & $\begin{array}{l}\text { - loss of control } \\
\text { - loss of privacy and control over } \\
\text { bodily functions } \\
\text { - bodily injury } \\
\text { - separation from family and } \\
\text { friends } \\
\text { - painful, invasive procedure } \\
\text { - fear of death }\end{array}$ & $\begin{array}{l}\text { - displays increased sensitivity to } \\
\text { the environment } \\
\text { - demonstrates detailed recall of } \\
\text { events to self and other patients }\end{array}$ & $\begin{array}{l}\text { - choice opportunity } \\
\text { - privacy } \\
\text { - safety } \\
\text { - family } \\
\text { - social support } \\
\text { - distract from disease or death }\end{array}$ \\
\hline $\begin{array}{c}\text { adolescent } \\
\text { (12 to } 18 \text { years) }\end{array}$ & $\begin{array}{l}\text { - loss of control } \\
\text { - fear of altered body image, } \\
\text { disfigurement, disability, and } \\
\text { death } \\
\text { - separation from peer group } \\
\text { - loss of privacy and identity }\end{array}$ & $\begin{array}{l}\text { - displays denial, regression, } \\
\text { withdrawal, intellectualization, } \\
\text { projection, displacement }\end{array}$ & $\begin{array}{l}\text { - choice opportunity } \\
\text { - distract from disease or death } \\
\text { - social support } \\
\text { - privacy }\end{array}$ \\
\hline
\end{tabular}


히 성인과는 다르게 환경에 더욱 민감한 신생아 중환자실 (NICU) 환자에게 있어 소음의 수준이 높을수록 심장 박동 수, 혈압, 호흡수가 증가하고, 산소포화도가 감소하여 산소 치료가 더 필요하다는 연구결과(Slevin, et al., 2000)는 위 의 결과를 지지하고 있다. 즉, 치료를 위해 입원한 아동이 숼 수 있는 휴식공간은 다른 소음으로 인한 자극을 최소화 할 수 있는 공간이어야 한다.

\section{3) Safety}

안전은 아동 뿐 아니라 의료 시설을 이용하는 모든 환자 에게 최우선으로 고려되어야 할 요소 중의 하나이다. 특히, 모든 기능이 완전히 발달되지 않은, 성장과정상에 있는 아 동에게 있어서 안전은 더욱 중요할 것이다. 입원한 아동에 게 있어 질병의 전염이나 낙상과 관련된 안전이 특히 중요 하다. 여러 연구에서도 접촉에 의한 감염을 예방하고 통제 하는 환경적 접근이 효과적임을 나타내고 있다. 즉 알콜 손 소독제를 배치하거나, 청결을 유지하기 쉬운 가구와 벽지 등이 효과적이었다(Ulrich, R. S. et al., 2008; 10)

\section{4) Choice Opportunity}

아동은 스스로 자율적으로 환경에 대한 탐색을 하면서 성장해나간다. 어린이 병원에서의 부정적 경험은 놀이로 서 완화될 수 있는데, 어린이 환자에게 놀이는 일상의 삶이 며 일이고, 즐거움과 자유로움이자 도전과 몰입이며, 그 자 체가 목표이기도 하고 수단이 되기도 한다(박영애, 김이진, 2010). 또한, 초등학교 입학 전의 풍부한 놀이경험이 전인 발달은 물론 이후 학업성취, 사회성, 창의성 등에 긍정적 영 향을 준다는 것은 이미 여러 나라에서 입증되었다(Miller \& Almone, 2009). 최근에는 뇌 과학 연구에서도 유아기의 놀 이가 행동, 사회, 정서, 인지 신체의 전인발달에 중요한 역 할을 한다는 사실이 입증되었다(Thompson, 2008). 따라 서 병원에서의 부정적인 정서적 반응을 완화하기 위해 놀 이와 같은 활동의 기회를 주는 것은 아동이 병원환경에 잘 적응하도록 하게 한다(Samela et al., 2010: 109).

\section{5) Light}

적절한 밝기는 통증을 완화시키고, 우울 감을 감소시키 는 결과를 가져온다(Ulrich, R. S. et al., 2008; 55). 아동의 경우에는 특히, 어두운 상황에서 두려움(Ball \& Bindler, 2007)을 느끼므로 밝은 공간이 필요하다.

\section{6) Privacy}

쉐프리(Shepley, 2005)에 따르면 프라이버시 유지는 자 신과의 상호작용을 가능하게 함으로서 학령기 이후의 아동 에게 중요한 요소가 된다. 또한 소아암을 않고 있는 어린이 환자에게 프라이버시 유지는 질병과 입원으로 인한 스트레
스에 적절히 대처할 수 있도록 하는데 긍정적 영향을 준다 (Rollins, 2009: 340). 여러 연령대가 함께 사용하는 휴게 공간에서 프라이버시를 유지하기 위해서는 가구나 장비를 활용할 수 있다. 특히 학령기 이후의 아동이 사용하는 곳은 별도로 배치되는 것이 효과적이다. 만약 공간이 협소한 경 우라면 간막이 벽과 같은 장치가 프라이버시 유지에 도움 이 된다(Ulrich, R. S. et al., 2008; 56).

\section{7) Social Support}

친구나 동료와 같은 사회적 지지는 학령기 이후의 아동 에게 특히 중요하다. 사회적 지지는 입원기간 동안에 아동 의 대처능력이나 건강측면에서 긍정적 영향을 주게 되는 데(Shepley, 2005: 315), 특히, 입원한 아동들 간의 관계 는 입원생활에 잘 적응할 수 있게 하는 중요한 요인이 된다 (Rollins, 2009: 341).

8) Distract from Disease and Death

유아기 이상의 입원한 아동들은 신체 손상이나 질병, 나 아가 죽음에 대한 두려움을 가지고 있다. 따라서 입원한 아 동의 정서적 안정 및 치유과정을 촉진하기 위해서는 그러 한 부정적 정서로부터 주의를 환기시킬 필요가 있다. 아이 젠(Eisen et el., 2008)은 아이들이 좋아하는 예술적 이미 지들이 병원에 있는 아동들에게 스트레스를 줄여주는 효과 를 가져 온다고 하였다. 또한 어른과 마찬가지로 자연경관 같은 요소들은 아동에게 고통과 같은 부정적 정서를 환기 시켜 긍적적 정서로의 전환에 효과적이다(Whitehouse et al., 2001: 303).

\subsection{Rest Space of Children's Hospital at Abroad}

문헌 및 인터넷 자료를 통해 2012년 미국에서 선정된 10 대 우수 소아병동 중에서 3 개소의 어린이 병원 휴게공간에 대하여 조사하였다(Table 3).

보스톤 어린이 병원(Boston Children's Hospital)은 396 병상으로, 1 년에 약 55 만명의 어린이를 치료한다. 휴게 공간에 자연환경이 담긴 사진과 작품으로 벽을 구성하고, 야외 휴게공간에는 자연친화적인 요소를 배치하여 환아의 주의를 분산시키고 있다. 특히, 별도의 갤러리를 설치하여 아이들의 상상력과 창의력을 키울 수 있는 작품을 전시함 으로서, 휴식과 함께 배움의 공간이 되도록 구성하였다. 이 와 같이 놀이를 포함한 학습 등의 다양한 행위를 할 수 있 도록 하여, 자유로운 선택권을 주도록 계획하였다. 휴게공 간은 환아들과 가족이 함께 사용하는 공간으로, 각 부서별 로 설치되어 있다. 가족은 의자에 앉아 쉴 수 있고, 매트를 깔아 아이들이 바닥에서 놀 수 있도록 하고 있으며, 친구들 이 병문안을 왔을 때 함께 사용할 수 있다. 또한 가족을 위 
[Table 3] Outline of Children's Hospital at Abroad

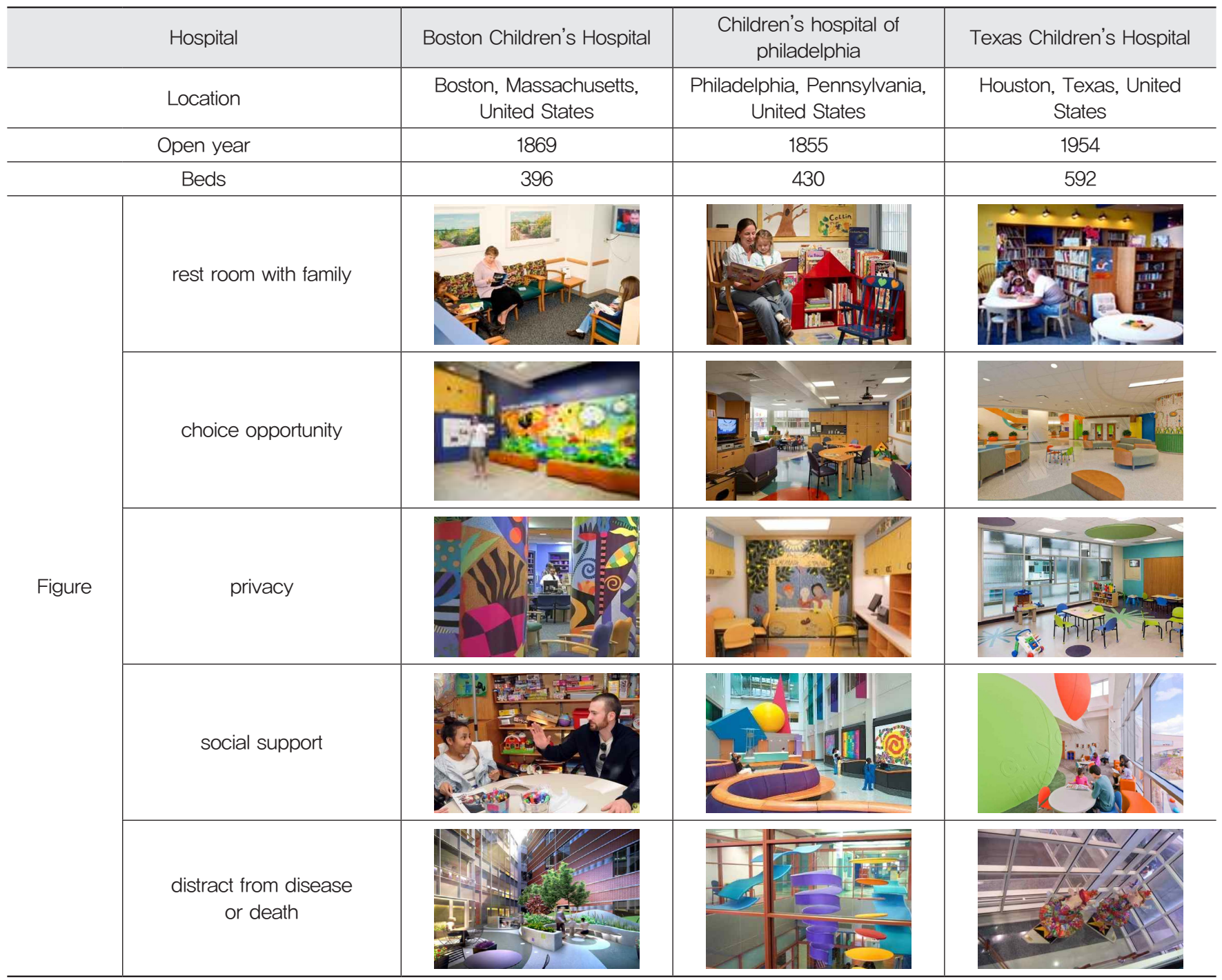

한 별도의 숙박시설이 있다.

필라델피아 어린이병원 (Children's Hospital of Philadelphia)에는 환아의 나이에 따라 적절한 활동을 할 수 있 는 놀이방이 있는데, 이것은 병동을 병원이 아닌 집과 같은 환경으로 구성함으로써 환아들의 스트레스를 저감하도록 하고 있다. 만약 아이가 직접 놀이방에 오지 못할 경우, 장 난감, 공예품, 책, 게임 등을 대여할 수 있으며, 대부분의 놀 이방은 가족과 함께 이용할 수 있다. 의료에 도움이 될 수 있도록 연령에 맞는 놀이를 제공하여 지루함을 방지하고, 선택할 수 있는 기회를 제공함으로서 정상적인 발달을 촉 진함과 동시에 질병에서 받는 스트레스를 감소시킨다. 특히 치료적 놀이를 진행하여 의료 상황이 발생했을 때의 대응 과, 경험의 숙달 및 표현을 용이하게 함으로서 놀이와 동시 에 치유를 가능하게 한다. 많은 사람들이 동시에 이용할 수 있는 휴게공간은 물론, 소수가 이용할 수 있는 공간도 제공 함으로써 환아의 프라이버시를 지킬 수 있게 배려하고 있 다. 가족이 휴식을 취하거나 텔레비전을 시청할 수 있는 가
족 라운지도 별도의 공간으로 제공하고, 병원 로비는 아이 들의 안전을 고려하여 소파를 배치하여 환아의 친구를 비 롯한 방문객들과 함께 이용할 수 있게 하였다.

텍사스 어린이병원 (Texas Children's Hospital)은 592 병상으로 아이들과 가족들을 위한 편의 시설이 별동의 한 개 층에 기능별로 배치되어 있다. 가족과 방문객들을 고려 한 숙박시설은 물론, 가족라운지에는 자동판매기와 전자레 인지를 구비하고 24 시간 개방하여 가족들의 이용에 불편이 없도록 하였다. 모든 연령대에 책, 보드 게임, 퍼즐과 영화 를 제공하는 도서관이 있어서 다양한 선택의 기회를 제공 하고 있으며, 환아 중 8 12세 아이들을 위해 비디오게임, 당구대, 축구 테이블, 컴퓨터 등을 갖춘 실이 배치되어있다. 또한 13 세 이상의 청소년들을 위한 청소년 방이 있는데 이 는 영화 감상, 비디오 게임 등을 실행할 수 있는 대형 스크 린 TV와, 음악을 듣고 공예품을 만들 수 있는 공간으로 구 성되어 있어 아이들이 자유롭게 행위 선택을 할 수 있고, 각 각의 행위에 맞는 공간에 가서 활동하기 때문에 서로에게 
소음을 비롯한 피해를 최소화 할 수 있다.

이상과 같이 외국의 경우, 어린이병원이 오래전부터 활 성화 되어 있어 대부분의 병원이 환아 뿐만 아니라 가족을 위한 공간을 별도로 갖추고 있었다. 또한, 환아의 안전을 우 선으로 고려하여 가구 및 시설을 배치하였고, 휴식을 위한 공간은 다양한 연령대를 고려해 나이에 맞는 활동을 할 수 있도록 연령별, 기능별로 공간을 따로 제공함으로서, 놀이 뿐만이 아니라 교육 등 환아들이 선택할 수 있는 다양한 행 위들이 이루어지도록 하고 있었다. 그럼으로써 환아들은 서 로 방해받지 않는 범위에서 활동을 할 수 있게 되고, 가족은 물론 환아의 친구들과도 자유롭게 놀이와 휴식을 취할 수 있었다. 실내 공기, 밝기 등 환아를 위한 최적의 환경은 물 론 자연친화적인 요소나 조형물, 미술작품 등을 활용하여 질병이나 죽음에 대한 생각으로부터 정서적 환기를 촉진할 수 있는 치유적 환경을 갖추고 있었다.

\section{Use and Need of Rest Space in Pediatric Ward in Seoul}

\subsection{Research Subjects}

조사대상시설은 서울에 위치한 우리나라의 대표적인 3 차 종합병원의 소아과 병동 3 개소를 선정하였다. 이것은 대 다수의 소아과 병동이 종합병원에 설치되어있으며, 규모가 상대적으로 작은 병원보다 적합하다고 판단하였기 때문이 다. 조사방법으로는 현장방문을 통한 설문조사, 관찰조사 및 사진촬영으로 소아병동 내 휴게 및 놀이공간을 조사하 였다(Table 4).

\subsection{Research Contents}

1) Present Condition

앞에 서술한 바와 같이, 아동의 성장, 발달 특성 및 입원 으로 인한 스트레스를 근거로 추출한 8가지 치유환경 요소 (가족이 함께 할 수 있는 환경, 소음, 안전, 선택권, 빛, 프라 이버시 지원 환경, 사회적 지지, 기분전환을 위한 환경)를 분석의 틀로 사용하여 조사대상 소아과 병동의 휴게공간에 대한 평가를 실시하였다.

평가는 휴게공간에 치유환경의 요인이 적용된 정도를 파 악하기 위해 2 명 이상의 연구자가 직접 방문하여 시행하였 다. 8가지의 치유환경 요소에 대하여 5점 척도 (1: 전혀 반 영되지 않았다, 3: 보통, 5: 매우 반영이 되어 있다)로 각 항 목 별 평균값을 산출하였다. 평가에 참여한 연구자들은 환 경에 대한 치유적 요소의 척도를 파악하여 배점하였으며, 분석결과는 다음과 같다(Table 5).

전반적으로 소아과 병동의 휴게공간 출입이 보호자를 포 함한 가족도 가능하여, 함께 이용할 수는 있었지만 아이를 감시하는 것 이외에 별도로 보호자 시설은 미비하였다. 실 내 환경을 조성하는 공기, 밝기, 온도 등은 불쾌감을 조성하 지 않았고, 소음 역시 크게 문제되지 않았으나, $\mathrm{H}$ 병원의 경 우, 공간이 협소하여 공간 내에서 발생하는 대화 내용이 들 렸다. 공간을 구성하는 시설이 아이들에게 위험하거나 신체 크기에 맞지 않아 안전함이 부족하였고, 실내에 구비되어 있는 가구와 집기들이 매우 한정되어 있어 행위에 대한 선 택권이 없었다. 환아의 가족 이외의 방문객들이 공간 이용 에 있어서 큰 어려움은 없었으나, 아이들이 갖고 있는 질병

[Table 4] Outline of investigated General Hospital

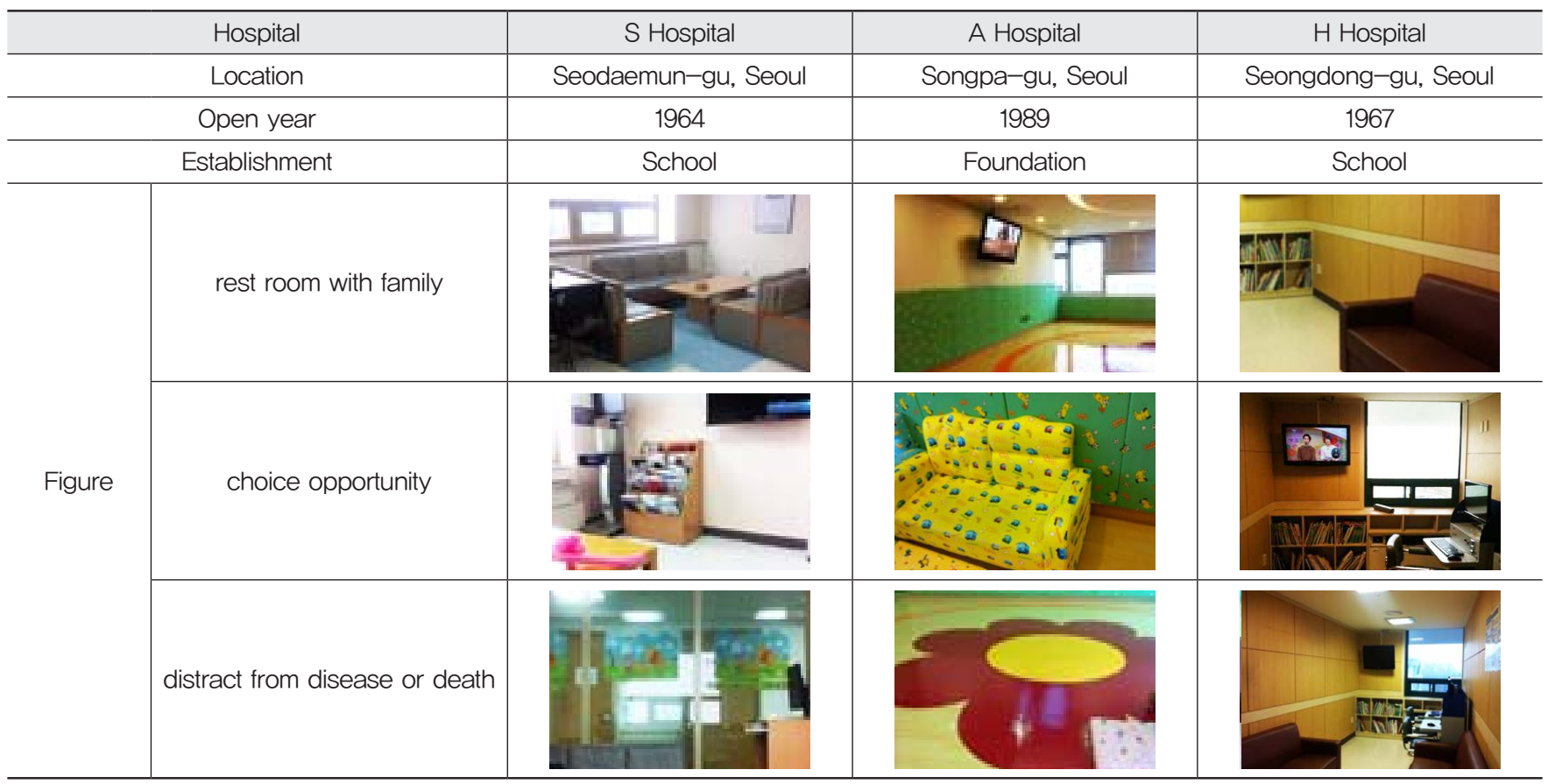


[Table 5] Present Condition of Rest Room

\begin{tabular}{|c|c|c|c|c|}
\hline $\begin{array}{l}\text { Healing } \\
\text { Factor }\end{array}$ & $\begin{array}{c}\text { S } \\
\text { Hospital }\end{array}$ & $\begin{array}{c}\text { A } \\
\text { Hospital }\end{array}$ & H Hospital & Average \\
\hline Family & 4 & 4 & 3 & 3.7 \\
\hline Noise & 3 & 4 & 2 & 3 \\
\hline Safety & 2 & 4 & 1 & 2.3 \\
\hline $\begin{array}{c}\text { Choice } \\
\text { Opportunity }\end{array}$ & 2 & 1 & 2 & 1.7 \\
\hline Light & 4 & 4 & 4 & 4 \\
\hline Privacy & 3 & 3 & 1 & 2.3 \\
\hline $\begin{array}{l}\text { Social } \\
\text { Support }\end{array}$ & 3 & 4 & 3 & 3.3 \\
\hline $\begin{array}{l}\text { Distract } \\
\text { from } \\
\text { Disease or } \\
\text { Death }\end{array}$ & 2 & 3 & 1 & 2 \\
\hline Average & 2.9 & 3.4 & 2.1 & 2.8 \\
\hline $\begin{array}{l}\text { synthesis } \\
\text { evaluation }\end{array}$ & $\begin{array}{c}\text { 선택의 } \\
\text { 기회나 } \\
\text { 기분전환할 } \\
\text { 수 있는 } \\
\text { 부분이 } \\
\text { 부족함 }\end{array}$ & $\begin{array}{c}\text { 안전한 } \\
\text { 공간이지만, } \\
\text { 선택의 } \\
\text { 기회가 } \\
\text { 현저히 } \\
\text { 부족함 }\end{array}$ & $\begin{array}{c}\text { 안전에 대한 } \\
\text { 부분이 } \\
\text { 부족하고 } \\
\text { 프라이버시 } \\
\text { 유지가 } \\
\text { 어려움 }\end{array}$ & - \\
\hline
\end{tabular}

에 대한 두려움으로부터 주의를 분산시킬 수 있는 요소는 찾아보기 힘들었다.

한편, 또 다른 조사로서 설문을 하였는데, 어린이가 설문 지를 이해하기 어렵다는 점을 고려하여 환아의 보호자를 대상으로 하였다. 설문내용은 "현재 휴게 공간을 이용하는 데 있어서 편리한 점, 불편한 점과 치유적 환경 요소를 제시 하며 중요하다고 생각되는 순서대로 순위 (1위 3위)를 부 여해 주십시오”로서 구성되었다. 각 병원당 3 4명의 보호 자를 중심으로 한 설문 결과는 [Table 6]과 같다.

설문결과, 아이들이 공간을 이용하는데 무엇보다 안전 과 프라이버시의 유지가 가장 중요한 것으로 나타났다. 또한 보호자와 동행하여 공간을 이용하는 아이들이 많아 아동 뿐 아니라 보호자를 비롯한 가족을 위한 공간 및 시설 이 요구되었고, 아동이 휴게공간에서 할 수 있는 행위가 다 양해 선택의 기회가 많이 주어지길 원했다. 다음으로 환아 들이 질병이나 죽음으로부터 받는 스트레스를 해소하기 위 한 기분을 전환할 수 있는 환경적 요소가 중요하게 나타났 다.

\section{2) Other Opinions}

치유적 환경에 관련된 요구사항 이외에 기타 의견도 수 집되었다. A 병원의 경우, 연령대 별 공간의 분리를 요구하 였다. 갓난아이일 경우, 좀 더 격리된 공간이 필요하다는 의 견이 있었다. 또한, 불쾌한 냄새가 나지는 않지만 환기가 어
떻게 이루어지는지 알 수 없었고, 비치된 장난감 등 놀이기 구가 없어 휴게공간에 와도 아이들이 놀 수 없었으며, 일정 시간 이후에 운영을 하지 않아, 야간 시의 이용을 요구하였 다.

$\mathrm{H}$ 병원의 경우, 공간이 너무 협소하여 보호자가 함께 있 을 수 있는 공간도 부족하고, 아이들이 할 수 있는 행위가 정해져 있어 다양한 놀이기구를 필요로 하였다. $\mathrm{S}$ 병원의 경우, 가구 시설물 및 집기류 등은 아이들을 위한 가구사용 및 아이들이 활동하는데 필요한 놀이감 등이 필요하다고 하였다.

[Table 6] User Preference

\begin{tabular}{|c|c|c|c|c|c|c|c|c|c|c|c|c|}
\hline \multirow{2}{*}{$\begin{array}{c}\text { Healing } \\
\text { Factor }\end{array}$} & \multirow{2}{*}{\begin{tabular}{|c|} 
sum \\
5
\end{tabular}} & \multicolumn{4}{|c|}{$\begin{array}{c}\text { S } \\
\text { Hospital }\end{array}$} & \multicolumn{4}{|c|}{$\begin{array}{c}\text { A } \\
\text { Hospital }\end{array}$} & \multicolumn{3}{|c|}{$\begin{array}{c}\text { H } \\
\text { Hospital }\end{array}$} \\
\hline & & - & & & & & & & - & - & . & - \\
\hline Noise & 2 & & - & & - & & & & & & & \\
\hline Safety & 9 & - & - & - & - & - & - & . & - & & & - \\
\hline $\begin{array}{c}\text { Choice } \\
\text { Opportunity }\end{array}$ & 5 & & & - & & . & . & . & & - & & \\
\hline \multicolumn{13}{|l|}{ Light } \\
\hline Privacy & 9 & & - & - & & - & - & - & - & - & - & - \\
\hline \multicolumn{13}{|l|}{$\begin{array}{l}\text { Social } \\
\text { Support }\end{array}$} \\
\hline $\begin{array}{l}\text { Distract from } \\
\text { Disease or } \\
\text { Death }\end{array}$ & 3 & - & & & - & & & & & & ! & \\
\hline
\end{tabular}

\section{Result}

문헌고찰을 통한 어린이 입원환자에게 필요한 치유적 환 경 요소를 토대로 해외 어린이 병동의 휴게공간과 국내 어 린이 병동의 휴게공간을 비교한 결과는 다음과 같다.

\section{1) Family}

외국 사례의 경우, 모든 어린이 병동의 휴게공간은 가족 이 함께 사용할 수 있을 뿐 아니라, 가족을 위한 가구배치 나 충분한 공간이 확보되어 있었다. 즉, 가족과 함께 할 수 있는 공간 및 가구에 대한 배려가 존재하고 있었다. 그러나 국내의 경우, 평균 3.7 점으로 가족과 함께 출입은 가능하지 만, 가족과 함께 할 수 있는 공간이나, 가구들이 부족하였 다. 몇 개의 의자만 일렬 혹은 둥근 형태로 나열되어 있는 경우가 많았고, 공간 역시 협소하였다.

가족의 지지는 어린이의 건강상태뿐만 아니라, 병원 및 돌봄에 대한 만족도를 높이고, 돌봄의 질을 높일 수 있다 
(Kuhlthau, K. A., et al., 2011; 136). 따라서 어린이 병동 의 휴게공간은 보호자도 함께 사용할 수 있는 공간으로 시 설을 구비하여 아이와 함께 공간 이용이 가능하고, 아이를 감시하면서 휴식을 취할 수 있는 공간 및 가구를 제공할 수 있어야 한다.

\section{2) Noise}

문헌고찰을 통해, 소음이 중요한 요소임을 확인하였으 나, 해외 사례의 경우, 직접적인 확인은 본 연구에서 제한되 었다.

연구대상병원에 대한 소음에 대한 평가결과는 평균 3점 으로 옆 병실이나 복도, 혹은 협소한 휴게공간으로 인해 불 필요한 소음이 적지 않게 들렸다. 환자뿐만 아니라 환자에 대한 돌봄의 질을 결정하는 의료진에게도 소음은 가장 중 요한 스트레스원 중의 하나이고((Varni, Burwinkle et al. 2004); 63), 휴게공간은 여러 명이 사용하는 공간인 만큼, 외부에서 들려오는 소리를 차단할 수 있어야 하고, 공간 내 에서의 소음을 적절히 유지 할 수 있도록 하는 연령별 공간 구획이 필요하다.

\section{3) Safety}

안전에 관한 부분에서 국내 환자의 보호자들이 가장 중 요하게 생각하고 있고, 문헌에서도 중요성이 강조되고 있었 다. 해외사례의 경우, 가구의 형태면에서 안전적인 요소를 고려했음을 알 수 있었다. 관찰한 국내 병원의 평균은 2.3 점으로 대상병원 중 한 곳에서는 안전을 고려하여 의자를 모두 없애고, 신발을 벗고 들어가는 넓은 방과 같은 시설에 사방 벽면 높이의 $1 / 2$ 에 해당하는 아래 부분에 $5 \mathrm{~cm}$ 두께의 쿠션과 어린이용 쇼파 두 개, 2 인용 어린이 매트가 설치되 어 있었다. 반면, 국내의 다른 2 병원의 경우, 감염을 우려한 세면대나 손 소독제는 모두 갖춰져 있었지만, 의자의 유형 이나 배치, 혹은 약물자동주입기 사용과 관련된 전원 콘센 트의 위치 등은 안전을 고려하지 못한 모습이 관찰되었다.

병원은 일반적으로 안전하다고 생각하는 경향이 많아서, 성장발달 과정상 아직 미숙한 어린이들은 병원환경에서 오 히려 낙상과 같은 사고가 자주 일어난다(DA RIN DELLA MORA R., et al., 2012; 467). 따라서 아이들에게 위험한 기구는 최대한 배치하지 않고, 공간 내에 배치되는 가구들 은 아이들의 눈높이에 맞으며, 모서리 부분은 둥글게 처리 된 것을 이용해야 한다. 또한 내부에 단차가 있을 경우, 걸 려 넘어지지 않게 경사로를 두고, 운동능력이 미숙한 어린 연령의 아이들이 사용하는 공간의 바닥은 쿠션의 기능을 하도록 매트리스 기능의 바닥재를 사용하는 것이 보다 안 전한 환경을 유지할 수 있다. 약물자동주입기를 사용하는 경우, 충전을 위한 콘센트는 전선으로 인해 넘어질 우려가 없도록 여러 곳에 설치해야 한다.
4) Choice Opportunity

아동에게 있어 선택의 기회는 자율성을 높여주어 병원에 서의 적응을 도와줌에도 불구하고, 국내 병원의 휴게공간에 는 아동의 활동을 고려한 놀이감이 거의 관찰되지 않았다. 본 연구에서 관찰한 병원 세 곳의 평균은 1.7 점으로 이들 중 두 곳은 어린이를 배려한 물건이 책 이외에 거의 없었으 며, 한 곳에서 어린이용 소파만을 관찰할 수 있었다. 해외의 경우, 어린이용 놀이감이나, 기구, 도서 등을 배치한 모습을 관찰할 수 있었다.

질병으로 인해 입원을 하고 있는 어린이도 끊임없는 성 장 발달 과정에 있으므로, 다양한 선택이 제공되는 놀이로 어린이의 성장 발달을 증진시킬 수 있어야 한다. 영유아/학 령전기/학령기/청소년으로 나뉘어 각 연령별 공간을 확보 하고, 이들의 영역은 연령에 맞는 놀이기구 및 가구를 배치 할 수 있어야 한다. 또한, 필요시 가구의 이동이 가능하도록 하여 효율적으로 공간을 이용할 수 있게 한다. 학령전기 및 청소년기의 아이들은 장난감과 놀이기구 보다는 컴퓨터 이 용을 더 필요로 하기 때문에, 컴퓨터 및 책장을 구비하여 좀 더 다양한 행위를 선택할 수 있는 기회가 필요하다.

\section{5) Light}

해외의 경우, 휴게공간의 밝기는 자연채광과 함께 밝은 모습이었고, 국내에서 관찰한 세 곳의 휴게공간 역시 평균 4 점으로 자연채광과 더불어 인공조명으로 인해 적절한 밝 은 환경을 유지하고 있었다.

빛은 인공조명이든 자연채광이든 사람에게 있어 통증, 및 우울을 감소시키고, 피로감을 줄이며, 심장주기를 조절 하는데 긍정적 역할을 한다(Adeniji, 2006; 49, Edelstein, $2008 ; 56)$ 더욱이, 어린이들은 발달과정상 어두음을 두려 워하는 경향이 있으므로 두려움을 느끼지 않고 편안하게 활동할 수 있도록 적절한 밝기가 유지될 수 있는 위치에 휴 게공간이 마련되어야 하고, 이를 조절할 수 있는 조명시설 이 필요하다.

\section{6) Privacy}

해외 병원의 휴게공간은 연령별 프라이버시를 위한 개 인 공간이 확보되어 있거나, 의자와 테이블의 위치가 개인 적 활동이 가능하게 배치되어 있었다. 그러나 국내의 경우, 평균 2.3점으로 아동의 연령을 고려한 곳은 관찰한 병원 중 한 개소도 없었으며, 개인적 활동이 가능한 곳은 개인용 컴 퓨터가 비치된 한 개소뿐이었다.

어린이의 발달 특성상 학령기 이후의 아동은 특히 프라 이버시 유지에 민감하므로 이를 위한 공간이 마련되어야 한다. 따라서 가벽의 기능을 할 수 있는 이동이 가능한 가구 를 이용하여 같은 공간을 이용하는 다른 사람에게 방해를 받지 않으면서 프라이버시를 유지할 수 있는 디자인이 필 
요하다.

\section{7) Social Support}

친구나 또래 관계와 같은 사회적 지지를 배려한 공간은 입원한 아동에게 긍정적 역할을 함에도 불구하고 국내 어 린이 병동의 휴게공간은 평균 3.3점으로 또래들과의 관계 를 위한 배려가 쉽게 관찰되지 않았다. 즉, 어른용 의자가 일렬로 배치되어 있거나, 단순히 방과 같은 공간, 혹은 중간 에 테이블이 있으며, 주위에 소파가 있는 구조 하나만 유지 하고 있었다. 반면, 해외의 경우 친구들과 함께 할 수 있는 놀이 감이나 기구들이 비치되어 있었고, 테이블의 배치 또 한 여러 그룹 활동이 가능하였다.

모든 연령의 어린이들은 친구를 사귀고 그런 친구들 과 함께 활동할 수 있는 병원환경을 원하고 또한 좋아한 다(Pelander \& Leino-Kilpi, 2010; 728, Fletcher et al., 2011; 40). 따라서, 그룹핑이 가능하게 원탁테이블과 의자 를 내부에 배치하고, 때에 따라 배치의 변경이 가능한 가구 를 활용해야 한다. 또한 연령별 또래들과 어울릴 수 있는 놀 이감을 비치해서 함께 할 수 있는 활동을 촉진할 수 있도록 해야 한다.

8) Distract from Disease and Death

병원에 있는 어린이 환자들은 고통과 질병, 죽음에 대한 두려움을 갖고 있기 때문에 휴게공간만이라도 그러한 두려 움에서 벗어나도록 하는 것은 환자의 치유과정에 긍정적 영향을 줄 것이다. 그러나 국내병원은 평균 2점으로 아동이 기분전환을 할 수 있는 그림이나 자연물 등이 전무한 상태 였고, 한 곳에서만 벽지와 바닥재가 아동이 좋아하는 캐릭 터 문양을 하고 있었고 또 다른 곳은 입구 쪽 창에 있는 그 림이 유일한 것이었다. 반면, 해외의 경우, 여러 가지 예술 적 요소를 활용하여 아동의 정서적 환기를 촉진할 수 있도 록 배려한 모습이 관찰되었다.

환자에게 있어 입원 중 병원환경의 색깔이나 디자인이 환자의 건강 및 회복에 중요한 요소가 되므로(English and Holm, 2004), 이를 촉진하는 디자인이 필요하다. 자연적 요소가 건강에 긍정적 효과를 가져 온다는 결과를 토대로 자연적 요소를 활용하거나 어린이들이 선호하는 디자인, 색 채를 활용하여 실내에 시각적인 요소를 포함할 수 있어야 한다. 이는 아이들에게 있어서 편안함과 즐거움을 유발하기 때문에 입원으로 인한 부정적 감정 및 이로 인한 악영향을 저감하는 효과를 기대할 수 있을 것이다.

\section{9) Synthesis evaluation according hospitals}

우리나라의 조사된 병원 세 곳의 치유적 환경 요소에 대 한 종합적 평가 결과는 5점 척도의 2.8점으로 평가되었다. 즉, 중간정도의 수준이다. $\mathrm{S}$ 병원의 경우 평균 2.9 점으로,
어린이를 위한 휴게공간이라기 보다는 어른 위주의 공간으 로 평가되었는데, 특히, 어린이들이 휴게공간에서 선택할 수 있는 기회가 책 이외는 없었고, 어린이의 기분을 전환할 수 있는 요소는 입구 쪽 창부분에 있는 그림 외에는 관찰되 지 않았다. B 병원의 경우, 평균 3.4점으로 조사대상 중 가 장 높은 점수를 나타났다. 특히, 낙상과 같은 상해로 부터의 안전을 고려한 공간임을 분명히 알 수 있었으나 넓은 공간 에서 어린이들이 가지고 놀 수 있는 놀이감은 어린이용 소 파 외에는 관찰되지 않았다. 그러나 넓은 공간의 확보로 인 해 여러 가족이 함께 공간을 활용할 수 있는 장점이 있었다. $\mathrm{H}$ 병원은 관찰한 세 병원 중 평균값이 전체 평균보다 낮았 으나(2.1), 컴퓨터가 비치되어 있어서 학령기 및 청소년들 이 사용할 수 있는 공간임을 확인할 수 있었다. 하지만, 상 대적으로 좁은 환경으로 인해 가족이나, 사회적 지지를 얻 을 수 있는 활동이 어려워 보였고, 기분전환을 할 수 있는 요소 또한 현저히 부족하다고 판단되었다(Table 5).

이상과 같이 국내의 어린이 병원은 해외 어린이 병원의 휴게공간과 비교할 때, 치유적 환경요소가 상대적으로 부 족하다고 판단된다. 반면에, 관찰한 세 곳의 휴게 공간 모두 에서 손쉽게 사용할 수 있는 손 소독제를 비치하고 있어서 감염으로부터의 안전은 어느 정도 확보하고자 하는 노력을 확인할 수 있었다.

\section{Conclusion}

본 연구 결과를 토대로 어린이 병동의 치유적 휴게 공간 계획을 위해 고려할 사항은 다음과 같다.

1) 어린이 병동의 휴게공간에서 고려되어야 할 치유적 환경요소는 8가지로 (1) 가족이 함께 할 수 있는 환경, (2) 소 음, (3) 안전, (4) 선택권, (5) 빛, (6) 프라이버시 지원 환경, (7) 사회적 지지(또래 관계를 지지할 수 있는 환경), (8) 기분전 환을 위한 환경 (distract from disease or death)으로 나타 났다.

2) 가족이 함께 할 수 있는 환경에 대한 평가결과는 평균 3.7점으로 상대적으로 높았지만, 여러 가족이 함께 공간을 활용하기에는 구조나 가구 배치 부분에서 부족하였다. 어린 이 병동의 휴게공간은 보호자와 함께 사용할 수 있는 공간 과 시설로 계획되어야 한다.

3) 소음에 대한 평가결과는 평균정도인 3점 수준이다. 외부에서 들려오는 소리를 차단할 수 있어야 하고, 공간 내 에서의 소음을 적절히 유지 할 수 있도록 연령별 공간구획 이 필요하다.

4) 안전에 대한 평가결과는 2.3점으로 낮은 수준이다. 아 이들에게 위험한 기구 배치를 피하고, 공간 내에 배치되는 가구들은 아이들의 눈높이와 치수에 맞아야 한다. 모서리, 단차, 바닥재 등의 사용에서 안전을 고려하고, 약물자동주 
입기를 사용하는 경우, 전선으로 인해 넘어질 우려가 없도 록 콘센트를 여러 곳에 설치한다.

5) 조사대상병원들의 선택기회를 제공하는 환경에 대한 평가는 평균 1.7 점으로 가장 낮게 나타났다. 가능한 영유 아/학령전기/학령기/청소년으로 나뉘어 각 연령별 공간을 확보하고, 연령에 맞는 놀이기구 및 가구를 배치할 수 있어 야 한다. 필요시, 가구의 이동이 가능하도록 하여 공간의 융 통성과 효율성을 확보하도록 한다.

6) 밝기는 평균 4점으로 대체적으로 잘 유지 되는 것으 로 평가되었다. 어린이들이 두려움을 느끼지 않고 편안하게 활동할 수 있도록 적절한 밝기가 유지될 수 있는 위치에 휴 게공간이 마련되어야 하며, 이를 조절할 수 있는 조명시설 이 필요하다.

7) 프라이버시 유지를 위한 공간에 대한 평가 결과는 평 균 2.3점이다. 이동이 가능한 가구를 이용하여 같은 공간을 이용하는 다른 사람에게 방해를 받지 않으면서 프라이버시 를 유지할 수 있는 디자인이 필요하다.

8) 사회적 지지를 배려하는 공간에 대한 평가는 평균 3.3 점으로 보통수준이다. 그룹핑이 가능하게 원탁테이블과 의 자를 내부에 배치하고, 때에 따라 배치의 변경이 가능한 가 구를 활용해야 한다. 또한 연령별 또래들과 어울릴 수 있는 놀이감을 비치해서 함께 할 수 있는 활동을 촉진할 수 있도 록 해야 한다.

9) 기분전환을 할 수 있는 공간에 대한 평가는 평균 2점 으로 해외사례에 비해 현저히 부족한 요소 중의 하나이다. 자연적 요소가 건강에 긍정적 효과를 가져온다는 결과를 토대로 자연적 요소를 활용하거나 어린이들이 선호하는 디 자인, 색채를 활용하여 실내에 시각적인 자극요소를 포함할 수 있어야 한다.

본 연구는 어린이 병동의 치유적 휴게공간 마련을 위한 기초적인 요소에 중점을 두고, 문헌을 통한 해외 자료와 국 내병원의 실태조사를 토대로 연구하였다. 비록 연구대상의 한계로 인하여 휴게공간의 모든 치유 요소에 대한 구체적 인 기준의 제시가 부족하고, 일반화가 제한적이라는 점이 지적될 수 있다. 그러나 본 연구의 결과는 환경에 취약한 아 동, 특히 병원에 입원한 아동이 이용하는 공간은 연령 특성 에 맞는 치유적 환경요소가 강조되어야 한다는 점을 지원 하고 있다. 기존의 여러 연구에서 일반적인 아동의 특성에 따른 의료공간을 계획하였다면, 본 연구는 입원한 아동의 반응을 고려한 치유적 요소를 활용하였다는 점에서 그 의 미가 있다.

\section{References}

1. Adeniji, T., 2006, Mood lighting assists patient healing. Health Estate, 60(5), 49-.50.

2. Ball \& Bindler, 2007, pediatric nursing: caring for children,
Pearson.

3. Blumberg R. (2006). "Design issues in hospitals: the adolescent client", Environment and Behavior, 38, pp293317.

4. Boston Children's Hospital www.childrenshospital.org

5. Children's Hospital of Philadelphia www.chop.edu

6. Choi, Ji Eun, Park, Soo Been, 2011, A Study on the Use and Needs for the Ward in Children's Hospital, Architectural Institute of Korea, 27(9).

7. DA RIN DELla MORA R., BAGNASCO A. \& SASSO L., 2012 In-hospital paediatric accidents: an integrative review of the literature. International Nursing Review 59, $466--473$

8. Edelstein, E. A. P., 2008, Building health. Health Environments Research \& Design Journal, 1(2), 54-.59.

9. Eisen S. L., Ulrich R. S,, Shepley M. M,, Varni J. W., Sherman S., 2008, "The stress-reducing effects of art in pediatric health care: art preferences of healthy children and hospitalized children”, Journal of Child Health Care 12, pp 173-190.

10. English, K. and Holm, R., 2004, "Ducks in Tennis Shoes", URL (8 March 2007): http://www.hospitalconnect.com/ articledisplay

11. Fletcher, T., Glasper, A., Prudhoe, G., Battrick, C., Coles, L., Weaver, K. \& Ireland, L., 2011, Building on the future: children"s views on nurses and hospital care. British journal of nursing (Mark Allen Publishing), 20, 39--45.

12. Koller D., McLaren, C., 2008, “Children's emotional responses to a pediatric hospital atrium", children \& society, pp1-14.

13. Kuhlthau, K. A., S. Bloom, et al., 2011, "Evidence for FamilyCentered Care for Children With Special Health Care Needs: A Systematic Review." AcademicPediatrics11(2):136-143.

14. Lee sin-ho,, Lee gi-ho, Lee jung-do, , Kim oon-sin, Lim gihye, Gi jae-hoon, Hu won-suk, 2006, “A Study on Developing Operation Plans and Management Guidelines for Children’s Hospitals‘, Korea health Industry development Institute.

15. Lee, Chong Guk, 2007, Nationwide survey of Discharge Data to Monitor the Long-term trends of Diseases and a Preliminary Study for the Constructing General Disease Surveillance System in Korean Children and Adolescents, the Korean Pediatric Society

16. Malkin, J., 1992, "Hospital interior architecture: Creating healing environments for special patient populations". New York: John Wiley.

17. Miller, E.,\& Almon, 2009, Crisis in the kindergarten: why children need to play in school: ML, Aliance for childhood.

18. Park, Jin Gyu, 2010, Research Paper : A Study on Healing Environments and Evidence-Based Design -Focused on 
Healthcare Environments in the United States-, Korea Institute of Healthcare Architecture, 17(1).

19. Park, Young Yae, Kim, Lee Jin, 2010, Maternal perceptions and expectations concerning children's play and support needed for its facilitation ,The Korean Association for Play Therapy, 15(2).

20. Pelander, T. \& Leino-Kilpi, H., 2010 Children"s best and worst experiences during hospitalization. Scandinavian Journal of Caring Sciences, 24, $726--733$.

21. Rollins, J. A., 2009, “The influence of two hospitals' designs and policies on social interaction and privacy as coping factors for children with cancer and their families." Journal of Pediatric Oncology Nursing, 26(6), pp340-353.

22. Samela M., Salantera S., Ruotasalainen T. Aronen E., 2010, Coping strategies for hospital-related fears in pre-schoolaged children. Journal of Paediatrics and Child health, 46, pp 108-114.

23. Severance Children's hospital http://sev.iseverance.com/ children

24. Shepley, M., 2005. The healthcare environment. In J. Rollins, R. Bolig, \& C. Mahan (Eds.), Meeting children's psychosocial needs across the health-care continuum, pp.313-349.

25. Slevin, M., Farrington, N., Duffy, G., Daly, L., \& Murphy, J. F., 2000, "Altering the NICU and measuring infants' responses." Acta Paediatrica, 89(5), pp577-581.

26. Small, L., 2002. "Early predictors of poor coping outcomes in children following intensive care hospitalization and stressful medical encounters." Pediatric Nursing, 28(4), pp393-398.

27. Texas Children's Hospital www.texaschildrens.org

28. Thomson, R. A., 2008, connecting neurons, concepts and people, : brain development and its implication, preschool policy brief, December, 17, National Institue for Early Education Research

29. Ulrich, R. S., C. Zimring, Zhu, X. DuBose, J., Seo, H. B., Choi, Y. S., Quan, X., Joseph, A., 2008, "A review of the research literature on evidence-based healthcare design." HERD,1(3), pp61-125.

30. Varni, J. W., T. M. Burwinkle, et al., 2004, "Evaluation of the built environment at a Children's Convalescent Hospital: Development of the Pediatric Quality of Life Inventory (TM) parent and staff satisfaction measures for pediatric health care facilities." JournalofDevelopmentalandBehavioralPediatri cs25(1):10-20.

31. Whitehouse S, Varni J, Seid M, Cooper-Marcus C, Ensberg M, Jacobs J, Mehlenbeck R., 2001, “Evaluating a children' $s$ hospital garden environment: utilization and consumer satisfaction", Journal of Environmental Psychology 21, pp301-314

접수 : 2012년 12월 31일 1차 심사 완료 : 2013년 1월 18일 게재확정일자 : 2013년 1월 18일 3인 익명 심사 필 